\title{
An original syllabus in photonics at the Ecole Généraliste d'Ingénieurs de Marseille
}

François Flory, Jean-Paul Fabre

François Flory, Jean-Paul Fabre, "An original syllabus in photonics at the Ecole Généraliste d'Ingénieurs de Marseille," Proc. SPIE 9663, Eighth International Topical Meeting on Education and Training in Optics and Photonics, 966305 (6 October 2003); doi: 10.1117/12.2207313

SPIE Event: Eighth International Topical Meeting on Education and Training in Optics and Photonics, 2003, Tucson, Arizona, United States 


\title{
An original syllabus in photonics at the Ecole Généraliste d'Ingénieurs de Marseille
}

\author{
François Flory, Jean-Paul Fabre \\ Ecole Généraliste d'Ingénieurs de Marseille, Dom U. de St Jérôme 13397 Marseille Cedex 20 France \\ Phone : 33 (0) 4912880 58; Fax : 33 (0) 4912888 13; e-mail : francois.flory@enspm.u-3.mrs.fr
}

\begin{abstract}
With the creation of a new school of engineers which is part of the French system of the "Grandes Ecoles" a deep reflection based on the experience of three schools, which are merging, has been led. The objective is to prepare highly selected students to meet the need for highly qualified scientists who can become highly qualified managers. The program of education is made of general courses in mathematics and sciences with deepening fields chosen by the students. Optics and photonics are very important parts of the proposed syllabus.
\end{abstract}

(C) 2003 Optical Society of America

OCIS codes: (000.0000) General

The French " Grandes Ecoles " are composed of small size institutions delivering degrees after the longest curriculum before a doctorate. These institutions are called " Ecoles d'ingénieurs" in France but it must be noticed that "Ingénieur" comes from the Latin word "genuis" or "ingenium" meaning talent, intellect. In English "Engineer" comes from "engine" that the person having the hands on something to operate it [1].

A little bit more than one percent of a class of age enters the two-year preparatory classes, after a dossier selection process. Students can choose between the different " Grandes Ecoles" depending on the results they obtained in competitive entrance exams. The selection process is based on working capacity (preparatory classes are quite demanding) and the mastering of abstraction measured through an extensive use of mathematics. The recruitment is also opened to high potential foreign students. The selective process is necessary to have students capable in succeeding a dense education for three years.

\section{Creation of the "Ecole Généraliste d'Ingénieurs de Marseille"}

Photonics is a strongly multidisciplinary field. Highly skilled people in this field have a wide knowledge in physics associated with specific competences in optics. In Marseille, after the experience of forty years of teaching to "ingénieurs", the Ecole Nationale Supérieure de Physique de Marseille decided to merge with two other schools of "ingénieurs" to strengthen the delivered education and to meet the need of companies for managers. The new school, called "Ecole Généraliste d'Ingénieurs de Marseille" (EGIM), delivers a high level of education for engineers and researchers capable in conceiving and managing complex systems, in particular optics based systems, in driving cross-disciplinary teams, in anticipating a quickly changing environment. The opportunity of the creation of this new, fully autonomous establishment belonging to the ministry of education and research, allows defining innovative pedagogical processes. In particular, beyond the conventional lectures, laboratories works, there is also the constant worry of relating one field to another, of keeping the student active, of keeping students' mind opened and curious, especially to cross-disciplinary approach, of caring about applications. The degree of the "Ecole Généraliste d'Ingénieurs de Marseille" is awarded to successful students after two years in preparatory classes, a competitive entrance exam and three more years including a final year where the students choose a field of interest. This field does not appear on the degree, which is not specialized even though the engineers can be considered as experts in the field. The students are normally 23 or 24 when graduated. They obtained the title of "Ingénieur de l'Ecole Généraliste d'Ingénieurs de Marseille" accredited by the "Commission du Titre d'Ingénieur».

2. Optics and Photonics are pluridiciplinary fields

Optics and photonics are key technologies for numerous application fields like telecommunications, health, microelectronics, defense and security, astronomy, transportations, ... They allows tens of millions people to communicate one with the other over the whole world, to cure people, to study the universe and as well to cool atoms as to make control fusion. It concerns also wide public applications like DVDs, illumination, screens, laser shows, ...

Very often photonics are only parts of complex systems. As an example a laser system needs competence in basic physics (Quantum Physics, electromagnetism, plasma physics, solid state physics, geometrical and Fourier optics, interferometry,

Eighth International Topical Meeting on Education and Training in Optics and Photonics,

edited by Barry L. Shoop, Grover Swartzlander Jr., Proc. of SPIE Vol. 9663, 966305

(c) 2003 SPIE, OSA, ICO · doi: 10.1117/12.2207313

Proc. of SPIE Vol. $9663966305-1$ 
non linear optics, light interaction with matter, signal processing,) as well as in technologies (material properties, optical interference coatings, mechanics, thermal problems, electronics, computering,).

So, beyond scientific and technical knowledge, theoretical and practical competences, a high level optician must be able to manage complex systems, to learn all his life long, but also must be capable in developing industrial processes.

More generally the worldwide economy and technologies, are quickly changing, the earth endures heavy pollutions, inequalities increases. Human and companies managements must not only rely on short-term economic criteria but sustainable development must also be considered. Scientists must be aware of their role. It then appears necessary to educate future managers so that, added to their excellence in sciences, they behave with an opened mind, as responsible citizens.

So the aim of the Ecole Généraliste d'Ingénieurs de Marseille is both to provide a high level scientific education and a humanist culture.

\section{Syllabus at the "Ecole Généraliste d'Ingénieurs de Marseille"}

The education of each student is based on a strong scientific basis and a wide general culture, extended by acquisition of competences in a more specific field. We are particularly concerned with the development of the entrepreneurship. In perfect agreement with Arthur Guenther [2], we want the engineers to have "transportable skills, critical thinking skills interpersonal skills, computer skills, communication skills".

As part of the common core, 104 hours of courses are given at all students, and 8 options of 24 hours are proposed directly in photonics. Other courses are of importance for photonics like mathematics, quantum physics, numerical analysis, computering, solid state physics, ... In their last year of study students can choose between ten different fields of interest, two of them being directly in photonics. Teaching in each field corresponds to 500 hours. Students must also perform a team transverse project, in which photonics can be a great part, and a training period of 5 months in a company. In their last year of study they also have the opportunity to perform one of the two master degrees proposed in optics (European Master of Sciences in Optics for the Information Society or master "Optique et Signal"). They can also perform a PhD for three more years in one of the international level laboratories of the institution.

So, a great part of the students can benefit of a high level of knowledge in photonics. Each student also benefits of 572 hours of courses aiming at developing a human dimension of the knowledge and competences. 240 hours of courses on foreign languages and cultures are included.

An assessment of competences is set when the student is accepted and regularly actualized so that the student can himself define his curricula and his professional project. We aim to have student actor of his own education.

The team transverse project is performed during the second year of study on a subject proposed by a company. It aims at developing teamwork abilities. A group of 6 to 8 students work together taking into account the costs, the delays, the human relations and produce a report at the end of the work. A professor accompanies the students. The evaluation is performed with the company.

The training period of 5 months in a company, which is a full part of the syllabus, is considered as a first experience in a professional environment. An oral presentation in front of a jury is considered together with a document for the evaluation. Numerous opportunities to perform a full year in a foreign university or in another French school of "Ingénieurs" are offered to students during their last year of study within the scope of exchange agreements.

\section{Research}

Most of the people teaching in the school have a $\mathrm{PhD}$ and lead a research. So, 9 laboratories are directly linked with the school, covering a wide scope of competences. Research in Mechanics, Acoustics, Chemistry, Mathematics, Computering and of course photonics (Fresnel Institute), is performed in the school, in association with the Centre National de la Recherche Scientifique and the universities of Marseille. Such a wide scope of competences gives the school a very important role in developing cross-disciplinary approaches. Doctoral students play a crucial role in research and they play a particular role in inter-linking teaching and research.

\section{Partnerships}

\section{Companies}

Partnership with companies is of major importance in the development of the "Ecole Généraliste d'Ingénieurs de Marseille". Several companies are represented in the Administrative Council that is presided by someone from the industry. They also are strongly represented in the professional orientation committee advertising the administrative council and the director on future evolutions. The scientific council that acts as a visiting committee for research also includes highlevel scientists from industry. Many people from industry take part in the education. The team transverse projects are performed in collaboration with companies and the end of study training period takes place in companies. The school is also very active in different thematic clusters of the region like the Optics and Photonics cluster (Pôle Optique et Photonique sud, POPsud), linking more than 70 companies, laboratories and institutions. The school houses POPsud. Lifelong training developed by the school is also very important in collaboration with companies. 


\section{Regional, national and international institutions}

The school obtains his main financial support directly from the Ministry of Education and Research, in particular through a four-year agreement. The school has also collaboration agreements with the three universities of Marseille and benefits of financial supports from the regional council of the Provence-Alpes-côtes d'Azur region, the Bouches-du-Rhônes department council and the town of Marseille. A strong collaboration with the commercial and industrial chamber of Marseille is under development.

Exchange students programs are working with nearly 20 high level universities worldwide. The European Credit Transfer System is operational and permits European students to attend some specific courses delivered in the school.

\section{Students activities and associations}

The student life is encouraged within associations. The student association, the sport association and the art association, together with different clubs (cinema, climbing, diving, music, oenology, astronomy,) aim at developing social life and initiatives. The students organize different thematic week, weekends and days all the yearlong.

\section{Conclusion}

The challenge of engineering education is to simultaneously prepare students for their first job and their career at least 25 years later. This of course applies to photonics. Photonics is and becomes more and more a trans-disciplinary field and this is also a challenge of education. To face theses challenges three "écoles d'ingénieurs" decided to merge and to create the

"Ecole Généraliste d'Ingénieurs de Marseille". This new institution has defined new curricula based on an innovative pedagogy. Multi-disciplinary basic knowledge is delivered and team project, training period and a strong human education are fully part of the syllabus. The students' highly selective process is applied to students entering the school so that they can face three years of extensive studies. The core education is delivered during 2 years and a more specific education that can be in photonics is delivered in the last year of study. High-level engineering education must be delivered in an environment of research and industry. Research, relations with companies, participation to the development of local economy, internationality, participation to networks are all necessary to a higher education institution. The "Ecole Généraliste d'Ingénieurs de Marseille" has defined its structure and its objectives in such a way. It aims at developing entrepreneurship, transportable skills, critical thinking skills, interpersonal skills, computer skills, leadership and communication skills.

\section{References}

1 Daniel Grimm, "The place of engineering training in society and its consequences on internationalization", Internationalisation of higher education conference, Wroclaw, November 1995

2 Milton M.T. Chang, “A life dedicated to optics and public service”, Photonics spectra, pp 46-47, March 2003 